\title{
A Discussão do Balanço Social na Grande Imprensa Brasileira: Um Estudo Exploratório no Jornal A Folha de São Paulo
}

\section{The Debate about Social Report in a Major Brazilian Press Organ: An Exploratory Study in A Folha de São Paulo}

\author{
José Ricardo Maia de Siqueira \\ Doutor em Engenharia de Produção - COPPE/UFRJ \\ Professor Adjunto da Universidade Federal do Rio de Janeiro \\ Av. Pasteur, 250 - Praia Vermelha - 22.290-240 - Rio de Janeiro - RJ \\ jrms@facc.ufrj.br \\ Alessandra de Sá Mello da Costa \\ Doutora em Administração - FGV/EBAPE \\ Professora Assistente da Pontifícia Universidade Católica - RJ \\ Rua Marquês de São Vicente, 225 - Gávea - 22.451-900 - Rio de Janeiro - RJ \\ amello9@terra.com.br \\ Moacir Sancovschi \\ Doutor em Administração - COPPEAD/UFRJ \\ Professor Titular da Universidade Federal do Rio de Janeiro \\ Av. Pasteur, 250 - Praia Vermelha - 22.290-240 - Rio de Janeiro - RJ \\ msancov@facc.ufrj.br \\ Thiago Maximiano de Oliveira da Silva \\ Graduado em Administração - UFRJ \\ Av. Pasteur, 250 - Praia Vermelha - 22.290-240 - Rio de Janeiro - RJ \\ tmaximiano@gmail.com \\ Carla Danielle Coloia de Carvalho \\ Graduada em Administração - UFRJ \\ Av. Pasteur, 250 - Praia Vermelha - 22.290-240 - Rio de Janeiro - RJ \\ coloia@gmail.com
}

\section{Resumo}

A publicação de balanços sociais por organizações empresariais é uma pratica recorrente na contemporaneidade. No entanto, apesar de haver uma legislação sobre este relatório desde a década de 1970 na França e da academia contábil brasileira já desenvolver estudos desde a década de 1980, o debate envolvendo balanço social só parece ter alcançado maior destaque na grande mídia brasileira, através da intervenção do sociólogo Herbert de Souza por meio de um artigo publicado em 1997. O presente estudo foi conduzido com o objetivo de investigar, através de um estudo de caso envolvendo o jornal Folha de São Paulo, o comportamento do debate de aspectos críticos relativos ao tema balanço social na grande imprensa brasileira, ao longo do período de 1994 a 2004. Para atingir esta meta foi elaborada uma revisão bibliográfica focada nas práticas atuais referentes a este instrumento, seguida por uma discussão relacionando a prática de construções ideológicas e a atuação da grande imprensa. 
Segue-se a estas a análise dos outputs da busca empreendida nos arquivo eletrônicos do jornal em questão, que foram divididos em seis categorias: artigo, comunicado, comunicado com cifras, carta de leitores, demonstrações contábeis e sem interesse. O presente estudo encontrou indícios da existência de relações de poder e construções discursivas ideológicas relacionados tanto ao conceito de balanço social quanto ao seu debate na sociedade através da mídia impressa.

Palavras-chave: Responsabilidade Social. Relatório Social. Balanço Social.

\begin{abstract}
The publication of social reports by organizations is a recurring practice in contemporary society. However, although there is legislation about this report since the 1970s in France and Brazil has developed academic accounting studies since the 1980s, the debate involving social reports only seems to have achieved greater prominence in the Brazilian media, through intervention of the sociologist Herbert de Souza via an article published in 1997. This study was conducted in order to investigate, through a case study involving the newspaper Folha de São Paulo, the debate on critical issues related to the topic social report in Brazilian press, over the period 1994 to 2004 . To achieve this goal it was created a literature review focused on current practices regarding this instrument, followed by a discussion relating the practice of ideological constructions and actions of the mainstream media. It is followed by the analysis of outputs of the search undertaken in the electronic files of the newspaper in question, which were divided into six categories: Article, statement, statement with figures, letters from readers, financial statements and uninteresting material. This study found evidence of the existence of power relations and ideological discursive constructions related to both the concept of social audit as to their debate in society through the print media.
\end{abstract}

Keywords: Social Responsibility. Social Report. Social Auditing.

\title{
1. Introdução
}

A temática sobre balanço social tem sido objeto de um considerável debate na academia brasileira, contudo, esta discussão parece perder intensidade na grande imprensa brasileira.

Este estudo tem por objetivo verificar, através da análise do caso da Folha de São Paulo, o comportamento do debate dos aspectos críticos relativos ao balanço social, em especial, se experimentaram um processo de desmantelamento, em conformidade com interpretação desenhada por Ventura (2003).

\section{Balanço Social: Prática Atual e Críticas}

Pode-se visualizar o balanço social como uma conta de benefícios e prejuízos prestado à sociedade semelhante à conta de lucros e perdas na contabilidade financeira (FLORES apud PINTO, 2003). A prática atual tem privilegiado a conceituação de balanço social como um documento publicado pelas empresas de forma voluntária, com periodicidade anual e que tem se centrado sobre as práticas, as ações e as atividades sociais desenvolvidas em benefício dos funcionários, das comunidades e do meio ambiente (DAVID; OTT, 2003; RIBEIRO; LISBOA, 1999; SANTOS; FREIRE; MALO, 1998; ZANELLA; DAVID, 2002). Tal fato tem motivado críticas por privilegiar os aspectos positivos da atividade empresarial.

Contudo esta não é a única crítica direcionada a atual prática de balanço social. Siqueira e Vidal (2003) examinaram um conjunto de 22 balanços sociais, emitidos por 
empresas dos mais diversos segmentos econômicos. A conclusão deste estudo foi que a prática de publicação de balanços sociais das empresas brasileiras analisadas apresenta diversos pontos negativos. Para chegar a este fecho se valeram de quatro parâmetros que podem ser utilizados para uma análise qualitativa dos balanços sociais brasileiros: (a) abrangência; (b) viés para potencialização de resultados; (c) comparabilidade; e (d) transparência. Tais parâmetros põem em relevância críticas que têm aparecido com certa freqüência na literatura acadêmica brasileira.

\section{Parâmetros Relativos aos Balanços Sociais}

Neste segmento são analisados os quatro parâmetros identificados por Siqueira e Vidal (2003).

\subsection{Abrangência dos Balanços Sociais}

A Fipecafi $(2010$, p. 7-8) postula que o balanço social possui quatro vertentes: o balanço ambiental, o balanço de recursos humanos, demonstração do valor adicionado e benefícios e contribuições para a sociedade. Estudos têm demonstrado que os balanços sociais brasileiros, com frequiência, não contemplam, em sua plenitude, o conjunto de informações que a sociedade demanda. Siqueira e Vidal (2003) encontraram diversos balanços sociais que não cobriram as vertentes do balanço ambiental e de recursos humanos, bem como, não apresentaram qualquer indicador relacionado aos aspectos redistributivos da atividade econômica. Pinto e Ribeiro (2004) apresentam opinião semelhante ao destacar que diversas informações relevantes não foram evidenciadas em nenhum dos relatórios analisados por eles. Cunha e Ribeiro (2004, p.12), em uma declaração que demonstra a limitação na abrangência das informações divulgadas, constataram que, de um total de 284 empresas analisadas, apenas "3 (...) apresentaram informações sobre todos os aspectos".

\subsection{Viés para Potencialização de Resultados}

O balanço social tem sido apresentado como um instrumento para divulgação de uma imagem corporativa positiva, não apontando, com frequiência, os aspectos sociais negativos das operações empresariais.

A ineficiência na evidenciação das externalidades das atividades econômicas é destacada por David e Ott (2003, p. 12) que afirmam que diferentemente "da contabilidade tradicional, que evidencia ativos e passivos, os Balanços Sociais em sua maioria buscam apenas demonstrar o ativo social das empresas, desconsiderando o outro lado, necessário para haver equilíbrio". Silva e Freire (2001, p.3) destacam o uso do balanço social como um destacado instrumento na construção da imagem social corporativa ao afirmar que são frequentemente considerados "como uma parte importante da política de relações públicas da empresa, onde são divulgadas as informações que sejam positivas em detrimento a uma verdadeira evidenciação do papel social da organização" (SILVA; FREIRE, 2001, p. 3). Pinto e Ribeiro (2004), em seu estudo envolvendo empresas industriais catarinenses destacam que nenhum dado que pudesse denegrir a imagem da empresa foi apresentado.

\subsection{Comparabilidade dos Balanços Sociais}

Esta é um dos pontos que mais têm sido destacados na literatura acadêmica brasileira. Guarneri, (2001, p. 159) chega a destacar que a inexistência de um padrão desperta a desconfiança dos usuários de que os balanços sociais estão se transformando em peças de marketing. 
A preocupação com a comparabilidade aparece nos escritos de Silva e Freire (2001, p. 3 ), segundo os quais "algumas entidades, em especial o IBASE no Brasil, tem procurado estabelecer um BST [balanço social tradicional] padrão (...). Entretanto, como o nível de divulgação do BST ainda encontra-se restrito (...), os modelos padrões de BST possuem um efeito limitado". Em um estudo onde são analisadas as informações sociais divulgadas pelas quinhentas maiores empresas SA não-financeiras do Brasil é destacado também os problemas existentes quanto à comparabilidade já que "a maioria das empresas ainda utiliza modelos diversos, muitos deles corporativos" (OLIVEIRA, 2003, p. 6).

Pinto e Ribeiro (2004) corroboram a posição anterior ao constatar que as entidades adotam diferentes modelos e publicam os dados das mais diversas maneiras, impossibilitando o usuário de fazer comparações entre empresas. E reforçam a percepção de gravidade da situação ao destacar que o modelo Ibase, já bastante consolidado apresentou diferenças de empresas para empresas. Problemas de padronização envolvendo o modelo Ibase também são destacados por David e Ott (2003, p. 12), pois “o que se pode vislumbrar é uma deficiência em expor questões mais delicadas a respeito das políticas da empresa. Informações a respeito da 'cidadania empresarial' foram as mais evitadas pelas empresas". Em outro estudo Miranda et al. (2001) ao analisar as 13 empresas que apresentaram uma demonstração com o balanço social, notaram que apenas 5 indicadores apareceram em 100\% dos demonstrativos. A demonstração do valor adicionado - uma das vertentes do balanço social segundo a Fipecafi (2010) - também apresenta problemas de comparabilidade. Silva et al. (2001) efetuou um estudo comparando as DVAs de 16 empresas nacionais e 10 internacionais. Foram detectadas discrepâncias - tanto na evidenciação da geração de riqueza, quanto na distribuição da riqueza gerada - nas empresas brasileiras entre si, nas empresas internacionais entre si e/ou entre os dois grupos.

\subsection{Transparência dos Balanços Sociais}

A questão da transparência nos balanços sociais brasileiros é abordada por David e Ott (2003, p. 12) ao afirmar que há ainda "muito a ser melhorado na qualidade dos Balanços Sociais, principalmente no que diz respeito à clareza das informações monetárias, na maioria dos casos apresentadas de forma resumida". A transparência das informações envolve além da existência de notas explicativas com qualidade e em quantidade suficiente, a existência de uma revisão por entidade independente. Pinto e Ribeiro (2004) destacam que nenhum dos balanços sociais foi auditado, nem tampouco apresentava qualquer nota explicativa.

\section{Ideologia e Grande Imprensa}

Fonseca (2003, p.2) afirma que no caso do Brasil

em razão de sua periodicidade diária, e de seu complexo aparato ou ferramental jornalístico, utilizado em larga medida de forma subliminar, os jornais são capazes de exercer uma influência sutil que lhes permite sedimentar (...) uma dada idéia, opinião ou representação nos grupos estrategicamente reprodutores de opinião, constituídos pelos estratos médios e superiores da hierarquia brasileira. Além do mais, objetivam a veiculação de idéias que influenciem a chamada opinião publica, os detentores do poder estatal, além de outros segmentos sociais estratégicos.

Também segundo este autor, "a grande imprensa, concebida como ator políticoideológico, deve ser compreendida como instrumento de manipulação de interesses e de intervenção na vida social" onde se misturam os interesses públicos e os interesses privados a partir das figuras dos leitores, dos donos do jornal e dos anunciantes. Também segundo este autor 
há no jornal, como um todo um núcleo ideológico, sintetizado em boa medida pelos editoriais, mas que perpassa (...) o periódico como um todo. Além do mais, a rígida hierarquia existente nas empresas jornalísticas demonstra claramente que, apesar desta complexidade, os seus proprietários possuem um amplo controle sobre o processo produtivo da informação, e, conseqüentemente sobre o produto final, as notícias, que são concebidas como mercadorias (FONSECA, 2003, p.3).

Sob esta ótica a grande imprensa atende aos interesses de uma elite dominante, sendo, portanto, parte do instrumental ideológico. É o que sinaliza Habermas (1984, p. 146) ao afirmar que a "partir do momento que a venda da parte noticiosa fica em relação de reciprocidade com a venda de anúncios, a imprensa (...) torna-se (...) ponto avançado dos interesses privilegiados privados, voltados para a opinião pública”. Esta visão é partilhada por Marx ao considerar fundamental que a imprensa deixe de ser uma indústria para que nela haja liberdade (KONDER, 1999, p. 24).

Esta posição é referendada pelo modelo de propaganda desenvolvido por Herman e Chomsky (2003, p. 62) para entender a dominação da mídia por uma elite, que opera através de cinco filtros de notícias, onde um deles é "a propaganda como principal fonte de recursos da mídia de massa".

E é a partir dessa relação ativa com a realidade (KNIGHTS; MORGAN, 1991; PHILLIPS; LAURENCE; HARDY, 2004) que o discurso permeia-se de ideologias e regras históricas anônimas, tornando visível dimensões específicas que são capazes de definir regras de comportamento (CABRAL, 1999; FARIA; MENEGHETTI, 2001) e posicionamentos políticos. De forma complementar, o discurso como prática ideológica constitui, naturaliza, mantém e transforma os significados do mundo de posições diversas nas relações de poder. Ambas as práticas são interligadas uma vez que a ideologia são os significados gerados em relações de poder como dimensão do exercício do poder e da luta pelo poder (BURRELL, 1988).

Cabe ressaltar a concepção marxista, segundo a qual a produção de um discurso é uma operação ideológica levada a termo como "tentativa de naturalizar a construção social da realidade, escamoteando as relações de poder" (JAIME JR., 2002, p. 81). Tal construção assegura que os interesses particulares daqueles que detêm o poder sejam vistos como os interesses gerais da sociedade. Ou, nas palavras de Marx e Engels (2005, p. 78), as "idéias (...) da classe dominante são, em todas as épocas, as idéias dominantes".

Acrescente-se ainda a idéia de que a libertação da ação dos pesquisadores em management só pode ser obtida quando eles começam a perceber os jogos de poder na sociedade, as normas estabelecidas pelas organizações, as hierarquias do controle sócioeconômico e a ideologia das formas de pensamento dominantes (GÓMEZ; SANTOS, 2000).

As ideologias são significações do mundo real, compreendido como sendo: (a) o mundo físico; (b) as relações sociais e (c) as identidades sociais. Segundo Motta (1984. p. 19), a ideologia apresenta-se como um conjunto de valores e crenças com o objetivo de manter determinada ordenação social e pressupõe a designação de lugares e papéis específicos dos diversos atores sociais "conferindo-lhes identidade e submetendo-os a uma determinada forma de dominação". Esta posição encontra-se em conformidade com o que Konder (2002, p. 10) denomina como significado forte de ideologia, ou seja, "uma distorção no conhecimento", em contraposição a um significado fraco de um simples conjunto de idéias.

Segundo Giddens (2003, p. 30), "a reificação das relações sociais, ou a naturalização discursiva das circunstâncias e produtos historicamente contingentes da ação humana, é uma das principais dimensões da ideologia na vida social". Para Fairclough (2001) as ideologias incorporadas nas práticas discursivas são mais eficazes quando se tornam naturalizadas e atingem o status de senso comum. No entanto, não são necessariamente estáveis em função da luta ideológica que existe dentro da dimensão da prática discursiva. Desta forma, a ideologia 
está localizada tanto nas ordens de discurso como nas condições para os eventos atuais e nos próprios eventos quando reproduzem e as transformam. As ideologias são transitórias e "(...) surgem, modificam-se e eventualmente desaparecem face ao movimento das relações sociais concretas" (MOTTA, 1984, p.21). Assim, por estar a ideologia sempre a serviço de um projeto, esta se traduz em uma prática política (MOTTA, 1984) onde se apresenta como a "capacidade de universalização de interesses/visão de mundo particularistas, o que implica fundamentalmente um contínuo e sinuoso processo de ocultação da realidade" (FONSECA, 2003, p.3).

Tal processo pode se dar através da contínua adaptação do capitalismo às críticas que lhe são direcionadas. É isto que demonstra Ventura (2003) ao analisar o atual discurso de responsabilidade social. Segundo a autora para

perpetuar-se, o capitalismo precisa (...) estimular e refrear, ao mesmo tempo, sua insaciabilidade, seu processo de acumulação ilimitada. É nessa dinâmica (...) que o espírito do capitalismo equaciona a tendência capitalista de auto-destruição com as exigências morais de bem-comum (VENTURA, 2003, p. 8).

Assim, o capitalismo, através de seus deslocamentos e de "transformações nos dispositivos que os acompanham contribuem para desmantelar a crítica que se torna inoperante, dando-lhe uma nova possibilidade de acumulação e lucros" (VENTURA, 2003, p. 14).

\section{O Problema}

A academia brasileira continua discutindo a questão da qualidade dos balanços sociais, contudo esta discussão parece não ser muito intensa na grande imprensa brasileira, aparentando conformidade com as características descritas em Ventura (2003).

Tendo em vista o exposto acima, pode se perceber em um jornal representativo da grande imprensa brasileira um movimento de desmantelamento da crítica, iniciada por Betinho em 1997, referente ao tópico balanço social, em conformidade com a descrição de Ventura (2003)?

\section{Objetivo do Trabalho}

Posto este questionamento, este trabalho tem por objetivo verificar, através de um estudo de caso envolvendo a Folha de São Paulo, se os aspectos críticos relativos ao tema balanço social experimentaram ao longo do período de 1994 a 2004 um processo de desmantelamento, dentro dos moldes descritos por Ventura (2003).

\section{Metodologia}

A mídia impressa, através da prática discursiva do jornalismo (FAIRCLOUGH, 2001) apresenta-se como neutra, racional e isenta de conteúdos ideológicos e posicionamentos políticos. De forma contrária, assume-se, neste trabalho, a premissa de que a mídia impressa apresenta-se como um importante veículo para a disseminação das ideologias na sociedade em função da abrangência de seu poder de comunicação e pela sua capacidade de publicizar idéias (FONSECA, 2003).

Identificar aspectos ideológicos no discurso da imprensa é fundamental, pois a comunicação de massa tem impacto central na análise da ideologia. Para Thompson (apud SCARBIERI, 2005, p.3), a sociedade contemporânea moderna e a presença da mídia tem sido responsável pela constituição do mundo como ele é hoje, onde: 
mais do que reproduzir dados da realidade, representa, por meio da linguagem, essa realidade, sendo escolhas específicas, utilizando-se de mecanismos que lhes são próprios e que podem, em determinados contextos, contribuir para a naturalização de crenças, papéis sociais ou interpretações da realidade idealizadas, ou seja, a imprensa pode veicular matérias que contribuam para estabelecer ou sustentar preconceitos e relações de poder.

Esta pesquisa é classificada, segundo Andrade (1995, p. 15), quanto aos seus objetivos como exploratória uma vez que se pretende analisar a temática de balanço social sob um novo enfoque. Se fará aqui uma análise do discurso na imprensa com o objetivo de identificar indícios de assimilação das críticas, trazidas à baila por Betinho sobre o tema balanço social no ano de 1997, por parte de um jornal representativo da grande imprensa brasileira.

\subsection{Coleta e Análise dos Dados}

Para atingir os propósitos deste trabalho foi selecionado o jornal Folha de São Paulo, tal seleção teve como base dois motivos principais. O primeiro deles refere-se à acessibilidade dos dados. A Folha de São Paulo oferece através de seu sítio um instrumento de busca que permite, através do uso combinado de palavras-chave, encontrar artigos que versem sobre o tema desejado.

Um segundo motivo refere-se às características do jornal. Por ser um dos jornais de maior circulação no país ele encontra-se dentro do perfil denominado genericamente como mídia de massa ou grande imprensa.

Para fins desta pesquisa serão analisados os outputs da busca empreendida nos arquivo eletrônicos da Folha de São Paulo. Estes outputs são material jornalístico com diversas naturezas que abordem, em diferentes graus de profundidade o tema balanço social.

Para a caracterização do processo de desmantelamento nos moldes descritos por Ventura (2003) espera-se, no caso do tema balanço social, um crescimento abrupto no número de artigos que versem sobre a temática, motivado pela intervenção de um nome de peso no cenário nacional, seguido por uma queda na quantidade de artigos que discutam tal necessidade, motivada por uma institucionalização da prática de publicação de balanços sociais. Espera-se ainda uma queda na qualidade das discussões como resultado direto de um processo de desmantelamento da crítica aliado à consolidação de práticas isomórficas de publicação de balanços sociais, conforme descrito por Ventura (2003).

Quadro 1 - Resultado da Coleta

\begin{tabular}{|l|c|}
\hline \multicolumn{1}{|c|}{ Anos Pesquisados } & Quantidade de Outputs \\
\hline-1994 & 3 \\
\hline-1995 & 2 \\
\hline-1996 & 1 \\
\hline-1997 & 20 \\
\hline-1998 & 5 \\
\hline-1999 & 3 \\
\hline-2000 & 6 \\
\hline-2001 & 5 \\
\hline-2002 & 4 \\
\hline-2004 & 11 \\
\hline
\end{tabular}

Dentro das circunstâncias específicas referentes a balanço social, o nome em questão é do sociólogo Herbert de Souza, mais conhecido como Betinho que em 1997 chama atenção para a necessidade da publicação de um balanço social através do artigo Empresa Pública e Cidadã. Visando identificar o crescimento abrupto seguido por uma queda no número de 
artigos sobre o tema foi selecionado o período de 1994 a 2004, para obtenção dos outputs dentro do site da Folha de São Paulo.

\begin{tabular}{|l|l|}
\hline \multicolumn{1}{|c|}{ Categoria } & \multicolumn{1}{c|}{ Quadro 2 - Categorização dos Outputs } \\
\hline Artigo & $\begin{array}{l}\text { Escrito de jornal que traga em seu bojo algum tipo de análise, de grau } \\
\text { variado, sobre o tema balanço social. }\end{array}$ \\
\hline Comunicado & $\begin{array}{l}\text { Declaração de pequeno porte que relata um acontecimento relativo a } \\
\text { balanço social sem proceder a qualquer tipo de análise. }\end{array}$ \\
\hline Comunicado com cifras & $\begin{array}{l}\text { Idem ao caso anterior, mas acompanhado de cifras referentes a balanço } \\
\text { social. }\end{array}$ \\
\hline Carta de Leitores & $\begin{array}{l}\text { Manifestação contrárias ou favoráveis à temática de balanço social, que } \\
\text { não nasçam da ação do corpo jornalístico. }\end{array}$ \\
\hline Demonstrações Contábeis & $\begin{array}{l}\text { Demonstrações financeiras publicadas pelas empresas que tragam em seu } \\
\text { corpo um balanço social. }\end{array}$ \\
\hline Sem interesse & $\begin{array}{l}\text { Material jornalístico apresentando, geralmente, um significado distinto } \\
\text { para a expressão balanço social. O caso mais comum é sua utilização no } \\
\text { sentido de "exame da situação social". }\end{array}$ \\
\hline
\end{tabular}

Os outputs foram conseguidos entrando-se com as palavras "balanço" e "social" na ferramenta de busca já mencionada, obtendo os seguintes resultados:

O padrão obtido se assemelha àquele esperado, apesar de uma pequena elevação no número de observações nos dois últimos anos - 2003 e 2004. Contudo faz-se necessário uma análise qualitativa dos outputs obtidos. Para uma melhor análise os outputs serão divididos em seis categorias conforme descrito no Quadro 2.

Para fins da análise qualitativa o intervalo de tempo de dez anos será dividido em quatro períodos: 1994-1996, 1997, 1998-2002 e 2003-2004.

\subsection{Limitações da Pesquisa}

Ao se buscar verificar se os aspectos críticos referentes à temática de balanço social sofreram um processo de desmantelamento nos moldes descritos por Ventura (2003), é de fundamental importância reforçar que tal análise foi desenvolvida apenas na Folha de São Paulo no período descrito, não podendo se generalizar tais resultados aos demais jornais representantes da grande imprensa no Brasil.

É importante destacar ainda que a única expressão utilizada no instrumento de busca foi balanço social. Não se utilizou outras expressões similares, tais como: relatório social e relatório de desenvolvimento sustentável, entre outros. Desta forma, não há como mensurar qual o efeito que se teria na coleta de dados com o uso destas expressões.

\section{Análise do Período de 1994 a 1996}

O período de 1994 a 1996 apresentou um total de seis outputs à consulta feita através do instrumento de busca, conforme se pode observar no Quadro 3 a seguir.

Neste período se observa um baixo volume de informações referentes a balanço social. Os dois únicos artigos observados são pequenas notas com considerações pouco aprofundadas sobre o tema. Em um dos artigos nota-se o uso de dois expedientes que são criticados por Siqueira e Vidal (2003) em suas análises sobre balanço social: preponderância na exposição de aspectos positivos em relação aos negativos e apresentação de aspectos negativos com atenuantes. 
Quadro 3 - Categorização dos Outputs no Período 1994-1996

\begin{tabular}{|l|c|}
\hline \multicolumn{1}{|c|}{ Categoria } & Quantidade de Outputs \\
\hline Artigo & 2 \\
\hline Comunicado & 1 \\
\hline Comunicado com cifras & 2 \\
\hline Carta de Leitores & 0 \\
\hline Demonstrações Contábeis & 0 \\
\hline Sem interesse & 1 \\
\hline
\end{tabular}

Se nota o uso do primeiro expediente quando o autor do artigo observa que o balanço social da Febraban "mostra as contribuições das instituições financeiras na área de treinamento, benefícios sociais, culturais e ação comunitária" (FOLHA, 1995). Esta descrição da proposta do relatório em questão traz em seu bojo um pressuposto de seu uso com a finalidade de construção de imagem corporativa.

Logo em seguida uma significativa redução de mais de 4,5\% da força de trabalho é acompanhada pela observação de que tal fato "demonstra (...) que os bancos se ajustaram para enfrentar a economia com menores taxas de inflação" (FOLHA, 1995), mimetizando o mesmo comportamento adotado pelas corporações em seus balanços sociais, ou seja, a utilização de atenuantes acompanhando informações socialmente indesejáveis.

A crítica ao desequilíbrio entre informações positivas e negativas encontra-se representada no outro artigo encontrado no período, que traz um pequeno relato do protesto do representante dos trabalhadores da Companhia Paulista de Força e Luz pela "omissão (...) de sindicâncias em obras de duas usinas" (FOLHA, 1995a).

\section{Análise do Ano 1997}

Trata-se da fase mais rica referente ao debate sobre balanço social, motivada pela discussão iniciada por um nome de relevo nacional - o sociólogo Herbert de Souza, o Betinho - que chama a atenção - com uma postura crítica - para a necessidade das empresas publicarem tal relatório. Conforme se pode observar no Quadro 4 a seguir, em nenhum ano se apresentou uma quantidade de outputs tão significativa, representando artigo de diferentes tendências e com análises mais profundas do que as apresentadas em anos anteriores e posteriores.

Quadro 4 - Categorização dos Outputs no Período 1997

\begin{tabular}{|l|c|}
\hline \multicolumn{1}{|c|}{ Categoria } & Qtde. de Outputs \\
\hline Artigo & 14 \\
\hline Comunicado & 1 \\
\hline Comunicado com cifras & 2 \\
\hline Carta de Leitores & 0 \\
\hline Demonstrações Contábeis & 2 \\
\hline Sem interesse & \multicolumn{1}{c|}{2} \\
\hline
\end{tabular}

A riqueza apresentada neste ano permite a segmentação da análise por tópicos.

\subsection{Conceito}

Uma grande variedade de conceitos é apresentada no período em questão. Nassif (1997) apresenta um conceito limitado do que é um balanço social, entendendo-o como "um conjunto de informações, publicadas anualmente junto com o balanço, relacionando as despesas das empresas em itens considerados sociais". Uma grande limitação deste conceito encontra-se na restrição da visão de balanço social como um rol de desembolsos realizados 
pela empresa, não mencionando a existência de indicadores qualitativos tão caros para a definição do perfil social da organização.

Do texto de Ioschpe (1997) se retira o conceito de que balanço social é o documento que objetiva "dar transparência e, conseqüentemente, poder de emulação ao investimento social que as empresas vêm fazendo silenciosamente e num volume e qualidade crescentes". Este conceito é inaceitável pois restringe o balanço social à divulgação de investimentos organizacionais no tocante a questões sociais, aproximando-o de seu uso como instrumento de marketing.

Para atingir seu objetivo que é "demonstrar quantitativa e qualitativamente o papel desempenhado pelas instituições no plano social" (SOUZA, 1997), o balanço social deve evidenciar tanto o que a empresa fez em prol da sociedade, quanto as externalidades da atividade econômica.

Assim, o conceito de Rioli (1997) se aproxima da idéia de balanço social como fonte de informação para a sociedade, definindo-o como uma ferramenta "de comunicação de responsabilidade empresarial, constituindo um conjunto de informações de natureza econômica, social, laborial e ambiental pelo qual se avalia o desempenho da empresa na comunidade na qual está inserida e com a qual interage". A expressão "conjunto de informações" é muito mais ampla do que uma relação de investimentos sociais, uma vez que admite a inclusão de indicadores - laborais, por exemplo - que permitam a averiguação de como a empresa está lidando com a mitigação de disparidades sociais - como as de gênero e raciais, por exemplo - ou de impactos ambientais.

Na mesma linha encontra-se a definição de Suplicy (1997) que entende o balanço social como um "documento pelo qual a empresa anualmente apresenta dados que permitam identificar a qualidade de suas relações com os empregados, com a comunidade e com o meio ambiente. É um registro do perfil social da empresa”.

\subsection{Obrigatoriedade}

Young (1997) se mostra contrário à obrigatoriedade de publicação do balanço social e afirma que "no contexto social (...) obrigar as empresas a publicar um balanço social representará um gasto extra a impactar a iniciativa privada que, como se sabe, navega em um ambiente turbulento, de alta competitividade e baixa rentabilidade".

Tal posicionamento do empresário levou a uma manifestação de Betinho sobre o tema, todavia, é interessante destacar que tal manifestação, dentro da amostra pesquisada, se deu de forma um tanto ambígua, podendo gerar dúvidas sobre sua opinião quanto à obrigatoriedade de publicação do balanço social.

Ao comentar o artigo de Young (1997), que se mostra favorável a uma adesão voluntária por parte das empresas, Betinho afirma ser essa "a solução ideal. Reflete uma disposição extremamente positiva por parte das empresas, uma das condições para que essa idéia dê certo" (Souza, 1997a). Parando-se por aqui a interpretação mais óbvia seria de sua opção pela voluntariedade, mas logo após o autor afirma que no "entanto, a vantagem de uma lei é representar legitimidade institucional".

É importante analisar esta passagem. Ao se buscar um conceito para ideal em Ferreira (2004) se encontrará aquilo "que é objeto da nossa mais alta aspiração intelectual, estética, espiritual, afetiva, ou de ordem prática" ou ainda aquilo que "é a síntese de tudo a que aspiramos, de toda a perfeição que concebemos ou se pode conceber". Assim o ideal existe no mundo das idéias, talvez como "modelo sonhado ou ideado pela fantasia de um artista, de um poeta" (FERREIRA, 2004), contudo Betinho como sociólogo tem bem clara a dimensão da imperfeição do mundo real, um mundo onde a legitimidade institucional é importante para 
tentar buscar um equilíbrio no jogo de forças do dia-a-dia. A ressalva de Betinho é, portanto, uma sutil opção pela obrigatoriedade.

Desconsiderando o artigo de Betinho foram encontradas quatro manifestações favoráveis à obrigatoriedade e duas contra. Rioli (1997) foi o outro que se posicionou contrário à obrigatoriedade afirmando que isento "de (...) divulgação compulsória, o balanço social permite à sociedade premiar as iniciativas empresariais nas diversas áreas de prioridade coletiva".

Apesar de Rioli (1997) ter apresentado um bom conceito de balanço social é preocupante seu posicionamento sobre a questão da obrigatoriedade, uma vez que a inexistência de um texto legal, definindo os indicadores a serem informados, permitirá às empresas uma livre escolha sobre o que publicar, tornando possível assim "à sociedade premiar as iniciativas empresariais", mesmo quando suas promotoras não forem socialmente responsáveis.

Nassif (1997) - um dos autores pró-obrigatoriedade - ao comentar o projeto que torna obrigatória a publicação do balanço social chega a afirmar que o "potencial transformador dessa lei poderá ser extraordinário”.

\subsection{Construção de Imagem}

A visão do balanço social como um instrumento para construção de uma imagem corporativa se imiscui dentro do texto jornalístico e tem como um bom exemplo a passagem onde se afirma que "o balanço social de uma empresa passa a ser valorizado junto com os seus ativos, os "shareholders", acionistas convertidos em "stakeholders", ativistas" (DINES, 1997). Há aqui uma assunção implícita de que o balanço social apresenta um viés onde a exposição dos aspectos sociais positivos da gestão empresarial terão preponderância sobre os negativos, evidenciando uma característica publicitária em detrimento da informacional. Do contrário o balanço social não teria o valor de um ativo, mas sim o peso de um passivo.

Para Betinho o "balanço social não pode ser uma peça de marketing, mas uma demonstração responsável de investimentos sociais realizados pela empresa" (SOUZA, 1997a).

Dimenstein (1997) o vê como um instrumento isento capaz de oferecer à sociedade uma mensuração adequada dos investimentos sociais e vai além, afirmando que empresas como Microsoft, Apple, Coca-Cola e McDonald's, entre outras, discriminam os brasileiros pois "se mostram muito mais envolvidas em projetos comunitários e educacionais nos EUA do que no Brasil", e acrescenta ainda que "inevitavelmente terão de explicar essa diferença".

A idéia de instrumento de avaliação do desempenho social corporativo encontra-se em outro artigo onde reforça que consumidor "responsável não é aquele que analisa apenas o que a empresa produz. Mas como produz" (DIMENSTEIN, 1997a).

A idéia de um instrumento de avaliação também está presente em Suplicy (1997) ao afirmar que um importante passo é "quebrar um pouco nossa tradição de fiscalizar apenas o que é público. Temos que continuar fiscalizando as instituições públicas, sim, mas também precisamos nos conscientizar de que as empresas privadas (...) são poderosos agentes sociais".

E a idéia de avaliação continua mais adiante ao afirmar que as empresas que não oferecem condições dignas de emprego, ou danificam o meio ambiente, ou se recusam a participar do desenvolvimento da comunidade precisam ser denunciadas. Ao contrário, aquelas que são exemplo de empresas-cidadã devem ser aplaudidas, incentivadas e prestigiadas (SUPLICY, 1997).

Tem-se aqui uma quebra de padrão onde se afirma que um balanço social tanto pode ser um ativo quanto um passivo, tudo dependerá da postura da empresa frente à sociedade.

A crítica ao uso dos balanços sociais como edificador de imagem é personificada pelos bancários na figura da CNB - Confederação Nacional dos Bancários - que divulgaram um 
"balanço anti-social" dos bancos revelando informações não apresentadas no relatório social da Febraban, tais como "dados sobre demissões e doenças profissionais no setor e sobre qualidade de atendimento nas agências" (FOLHA, 1997).

\section{Análise do Período de 1998 a 2002}

Nota-se no período de 1998 a 2002 uma queda significativa na quantidade de ocorrências referentes a balanço social - um total de 23 para um intervalo de cinco anos contra 20 observações em um único ano, no caso 1997. Observa-se também no Quadro 5 que a quantidade de material sem interesse para fins desta pesquisa é considerável - um total de onze.

Quadro 5 - Categorização dos Outputs no Período 1998-2002

\begin{tabular}{|l|c|}
\hline \multicolumn{1}{|c|}{ Categoria } & Qtde. de Outputs \\
\hline Artigo & 7 \\
\hline Comunicado & 0 \\
\hline Comunicado com cifras & 3 \\
\hline Carta de Leitores & 2 \\
\hline Demonstrações Contábeis & 0 \\
\hline Sem interesse & 11 \\
\hline
\end{tabular}

Do ponto de vista qualitativo as análises são muito menos aprofundadas do que as apresentadas no ano de 1997, adicionalmente pode-se dizer que são muito mais pobres do ponto de vista de diversidade de opiniões, apresentando com frequiência a temática com destaque para os aspectos positivos. Tal postura é claramente percebida em Villela (1999) ao afirmar que o balanço social é o documento que "reúne informações sobre as atividades desenvolvidas nas áreas de promoção humana e social e em educação, saúde, ecologia e cultura". E acrescenta ainda que é "por meio dele que a empresa comunica (...) onde, como e quanto está investindo em setores que beneficiam todos".

Não muito diferente é o conceito de balanço social apresentado onde se afirma que este "é um documento com informações sobre os projetos sociais de uma empresa" (FOLHA, 2002).

Há ainda um otimismo encontrado em vários artigos. Tal otimismo encontra-se presente em Ferreira (1998) ao afirmar que a "duras penas, o capitalismo aprendeu que o Estado não tem competência gerencial para cuidar sozinho (...) das coisas públicas que afetam diretamente os cidadãos. Por isso mesmo, o empresário moderno passou a assumir o dever de elevar o bem-estar (...) de seus empregados".

Encontra-se também na declaração do então ministro Paulo Renato, captada por Dimenstein (2000), de que existe "algo novo no ar, os empresários estão preocupados e se movimentam". Há que se ressalvar contudo que se trata de um otimismo não descompromissado, já que há "uma preocupação com a imagem".

E aparece ainda na matéria feita por Domenich (2001) que capta em uma entrevista a declaração de que as "empresas estão cada vez mais engajadas. (...) O importante é investir nos 53 milhões de excluídos".

Possivelmente o artigo mais significativo sobre o tema seja de Steinbruch (1998), que analisa os números do balanço social da CSN e chega a um conceito de responsabilidade social focado em aspectos operacionais que se aproxima de nenhuma responsabilidade social, quando se baseia em uma ótica de que esta é

o compromisso que uma organização deve ter para com a sociedade, expresso por meio de atos e atitudes que a afetem positivamente, de modo amplo (...) assumindo, assim, além das obrigações estabelecidas em lei, também obrigações de caráter moral, mesmo 
que não diretamente vinculadas às suas atividades, mas que possam contribuir para o desenvolvimento sustentável dos povos.

É significativo destacar ainda que a questão da obrigatoriedade do balanço social foi praticamente expurgada das páginas do jornal, já que há apenas duas menções sobre o assunto: um pequeno artigo mencionando a decisão da CVM de transferir a discussão da obrigatoriedade do balanço social para o congresso e um pequeno texto na seção Painel do Leitor. Ambos sem qualquer posicionamento em relação à questão.

\section{Análise do Período de 2003 a 2004}

O período de 2003 a 2004 é, aparentemente, uma quebra ao padrão apresentado nos últimos anos - apesar do número de observações anuais ser muito inferior ao apresentado no ano de 1997 - contudo, uma análise mais detalhada revela que isto não é verdade. Dos vinte e dois outputs, dez referem-se a material sem interesse para fins desta pesquisa e uma análise mais aprofundada revela baixa profundidade nos artigos, bem como, baixa variedade na diversidade de opiniões em relação ao tema.

Em um artigo onde são apresentados os resultados de um estudo sobre responsabilidade social são reveladas informações sobre balanço social demonstrando que nas empresas de grande porte - consideradas aqui como aquelas com 500 ou mais empregados - a prática de publicação de balanços sociais é muito mais significativa que nas empresas de pequeno - com até 99 funcionários - e médio porte - de 100 a 499 funcionários. No primeiro grupo $41,4 \%$ das empresas o publicam contra 5,6\% e $9 \%$ nos outros dois grupos, respectivamente (FOLHA, 2003).

No entanto esta mesma pesquisa revela que as empresas vêem o balanço social como um instrumento de construção de uma imagem corporativa positiva, já que apresentaram um alto grau de concordância com o tópico Fortalece a imagem que significa, segundo o exposto no artigo, que tudo "o que a empresa faz além do que a lei determina, e que é valorizado positivamente pela sociedade, deve ser amplamente divulgado em balanço social, pois isso gera repercussões positivas para sua imagem e para sua competitividade" (FOLHA, 2003).

Quadro 6 - Categorização dos Outputs no Período 2003-2004

\begin{tabular}{|l|c|}
\hline \multicolumn{1}{|c|}{ Categoria } & Qtde. de Outputs \\
\hline Artigo & 3 \\
\hline Comunicado & 3 \\
\hline Comunicado com cifras & 3 \\
\hline Carta de Leitores & 0 \\
\hline Demonstrações Contábeis & 3 \\
\hline Sem interesse & 10 \\
\hline
\end{tabular}

Em outro artigo o apelo da construção de imagem aparece de forma sutil nas declarações de um diretor do Citibank ao afirmar que a "contrapartida para a imagem é forte, mas não é nosso objetivo", no entanto o autor do artigo contrapõe mais adiante que apesar "disso, pela primeira vez neste ano o banco (...) deve divulgar seu balanço social para clientes via e-mail" (PRADO, 2003).

Um auto-interesse esclarecido também se encontra presente em um dos artigos analisados. Ele é visto na afirmação de que o "balanço social das corporações (...) ganhará maior atenção nos próximos anos, uma vez que as escolhas dos consumidores estarão mais atreladas a valores éticos" (RIBEIRO, 2003).

Este auto-interesse esclarecido não deixa de ser uma variante da visão do balanço social como instrumento de construção de imagem, já que parte de um pressuposto perigoso 
de que apenas empresas socialmente responsáveis publicam balanço social. Isto obviamente não é verdadeiro, já que empresas que não primam pelo respeito a valores caros à sociedade, podem selecionar apenas informações que vão ao encontro destes valores e organizá-las sob a forma de um relatório social.

Por fim, um conceito limitado de responsabilidade social - próxima à abordagem friedmaniana - é apresentado, onde se afirma que esta "se traduz em pagar impostos, gerar empregos e ofertar produtos de qualidade ao mercado" (FOLHA, 2003). Se analisada rigorosamente esta definição sequer atenderia a uma abordagem legalista, pois não faz referência ao arcabouço normativo existente na sociedade pertinente às questões ambientais e trabalhistas, por exemplo.

É importante destacar ainda que aparecem neste último período analisado três comunicados de publicação de balanço social, repetindo tendência que se observou desde o primeiro intervalo de tempo analisado. Estes comunicados podem ser vistos como representações dos deslocamentos do capitalismo visando tornar inoperante a crítica que lhe é feita, estando em conformidade à proposta desenvolvida por Ventura (2003, p. 14).

\section{Conclusões}

A partir da presente pesquisa, pode-se encontrar indícios da existência de relações de poder e construções ideológicas relacionadas tanto ao conceito de balanço social quanto ao seu debate na sociedade através da mídia impressa. Tais indícios apontam a utilização dos balanços sociais como ferramenta de construção de imagem. E neste caso, o processo de gerenciamento de impressões encontrou na sociedade brasileira um terreno fértil.

Há inclusive indícios de que o processo de edificação de estruturas ideológicas está se agravando. Quando Betinho fez sua apreciação crítica sobre o estágio da evidenciação dos aspectos sociais das atividades empresariais e chamou à baila a proposta de publicação do balanço social, veio no esteio de sua proposição um amplo debate sobre a questão. Nos últimos anos nota-se a consolidação em torno de propostas desmobilizadoras da sociedade referentes ao tema.

Um bom exemplo refere-se à questão da obrigatoriedade da publicação do balanço social. No ano de 1997 tratava-se de um tópico importante na discussão do tema, com uma quantidade de artigos pró-obrigatoriedade superior àqueles que se opunham. Nos últimos anos esta discussão praticamente desapareceu.

O próprio conceito de balanço social era amplamente debatido, havendo certa preponderância daqueles que destacavam uma característica de controle no instrumento. Ultimamente se firmou a visão de balanço social como instrumento de divulgação das ações corporativas em prol da sociedade.

Em suma percebe-se na amostra analisada um crescimento acentuado no número de artigos que versam sobre o balanço social no ano de 1997, logo após a intervenção de Betinho, seguido por uma acentuada redução neste número com o passar dos anos. A polêmica se reduz através da aceitação das práticas institucionalizadas de publicação de balanços sociais, legitimando-as. Tal descrição se coaduna com o processo - descrito por Ventura (2003) para o discurso de responsabilidade social - de desmantelamento da crítica aliado à consolidação de práticas isomórficas de publicação de balanços sociais.

Complementarmente, como uma imagem é construída primeiramente por meio de informações superficiais, infrequentes e mediadas através da mídia de massa, das aparições públicas e de fontes de segunda mão (ALVESSON, 1990; ALVESSON; DEETZ, 1998), o fórum disseminador, por excelência, da construção discursiva pretendida é a grande imprensa. 
Assim, a identificação de aspectos ideológicos no discurso da imprensa torna-se primordial por dois motivos. De um modo geral, pelo poderoso lugar ocupado na sociedade contemporânea pela mídia como formadora opinião e manipuladora de significados. E de um modo mais específico, pelo endosso ideológico às formas assumidas hoje pelos nãocompulsórios balanços sociais brasileiros, que não estão cumprindo o seu papel mais simples: o de ser um instrumento de prestação de contas do impacto social e ambiental das empresas na sociedade.

\section{Referências}

ALVESSON, M. Organization: From substance to Image. Organization Studies, p.373 394, 1990.

ALVESSON, M; DEETZ, S. Teoria crítica e abordagens pós-modernas para estudos organizacionais. In: CLEGG, S.;HARDY, C.; NORDY, W. R. ; CALDAS, M.; FACHIN, R.; FISCHER, T. (Eds.) Handbook de Estudos Organizacionais. São Paulo: Atlas, v.1, 1998. p. 227-266.

ANDRADE, Maria Margarida de. Como Preparar Trabalhos para Cursos de PósGraduação. São Paulo: Atlas, 1995.

BURRELL, G. PostModernism and Organizational Analysis 2: The contribution of Michel Foucault. Organization Studies, 9/2, 1988. p.221-235.

CABRAL, Augusto Cezar de Aquino. A Análise do Discurso como estratégia de pesquisa no campo da administração: um olhar inicial. Anais do XXIII Encontro da ANPAD, Foz do Iguaçu, 1999.

CUNHA, Jacqueline Venerosos Alves da; RIBEIRO, Maisa de Souza. Evolução e Diagnóstico Atual do Balanço Social. Anais do $4^{\mathbf{o}}$ Congresso USP de Controladoria e Contabilidade. São Paulo: 2004. Texto em CD-ROM.

DAVID, Afonso Rodrigo de; OTT, Ernani. Balanço Social: Uma Análise das Informações Evidenciadas pelas Empresas. Anais do $\mathbf{2 7}^{\circ}$ Enanpad. Atibaia: 2003. Texto em CD-ROM.

DINES, Alberto. A Moda da Ética e a Ética sem Dor. Folha de São Paulo, p. 4-9, 2 de agosto de 1997. Documento obtido no site http://fws.uol.com.br/folio.pgi/fsp1997.nfo em 27 de setembro de 2005.

DIMENSTEIN, Gilberto. Lei do Incentivo à Bobagem. Folha de São Paulo, p. 1-27, 6 de julho de 1997. Documento obtido no site http://fws.uol.com.br/folio.pgi/fsp1997.nfo em 27 de setembro de 2005.

DIMENSTEIN, Gilberto. Empresas privadas, como Telefônica, Bradesco e Itaú, apóiam projetos educativos e aprimoram imagem. Folha de São Paulo, p. C6, 12 de junho de 2000. Documento obtido no site http://fws.uol.com.br/folio.pgi/fsp2000.nfo em 12 de agosto de 2005. 
DIMENSTEIN, Gilberto. O Plano Real Acabou. Folha de São Paulo, p. 1-22, 22 de junho de 1997a. Documento obtido no site http://fws.uol.com.br/folio.pgi/fsp1997.nfo em 27 de setembro de 2005.

DOMENICH, Mirella. Companhias estão mais atuantes, mas a adesão precisa aumentar. Folha de São Paulo, p. Especial-10, 28 de outubro de 2001. Documento obtido no site http://fws.uol.com.br/folio.pgi/fsp2001.nfo em 12 de agosto de 2005.

FAIRCLOUGH, Norman. Discurso e Mudanca Social. Brasília: Editora UnB, 2001.

FARIA, José Henrique; MENEGHETTI, Francis K. Discursos Organizacionais. Anais do XXIV ENANPAD, Campinas, 2001.

FERREIRA, Edemar Cid. Repartir para Ganhar. Folha de São Paulo, p. 1-3, 11 de fevereiro de 1998. Documento obtido no site http://fws.uol.com.br/folio.pgi/fsp1998.nfo em 27 de setembro de 2005.

FERREIRA, Sérgio Buarque de Holanda. Novo Dicionário Eletrônico Aurélio - versão 5.0. Positivo, 2004. Documento em CD-ROM.

FIPECAFI. Manual de Contabilidade Societária: Aplicável a Todas as Sociedades de Acordo com as Normas Internacionais e do CPC. São Paulo: Atlas, 2010.

FOLHA de São Paulo. Ações em favor da comunidade serão avaliadas. Folha de São Paulo, p. C4, 13 de agosto de 2002. Documento obtido no site http://fws.uol.com.br/folio.pgi/fsp2002.nfo em 12 de agosto de 2005.

FOLHA de São Paulo. Balanço Social. Folha de São Paulo, p. 2-2, 12 de junho de 1995a. Documento obtido no site http://fws.uol.com.br/folio.pgi/fsp1995.nfo em 27 de setembro de 2005.

FOLHA de São Paulo. Bancários Divulgam Balanço “Anti-Social” dos Bancos. Folha de São Paulo, p. 2-5, 29 de agosto de 1997. Documento obtido no site http://fws.uol.com.br/folio.pgi/fsp1997.nfo em 27 de setembro de 2005.

FOLHA de São Paulo. Banco Seleciona Clientes para dar Empréstimo. Folha de São Paulo, p. 2-8, 31 de maio de 1995. Documento obtido no site http://fws.uol.com.br/folio.pgi/fsp1995.nfo em 27 de setembro de 2005.

FOLHA de São Paulo. "Raio-X da Responsabilidade Social". Folha de São Paulo, p. 2, 21 de dezembro de 2003. Documento obtido no site http://fws.uol.com.br/folio.pgi/fsp2003.nfo em 12 de agosto de 2005.

FONSECA, Francisco. A Grande Imprensa e a Constituição da Agenda Ultraliberal na Nova República. Estudos Históricos. CPDOC/FGV, Mídia, n.31, 2003/1.

GIDDENS, Anthony. A Constituição da Sociedade. São Paulo: Martins Fontes, 2003.

GÓMEZ, Ana Maria Dávila; SANTOS, Jair Nascimento. La Pédagogie Critique Comme une Stratégie Pour la Formatio du Manager. Anais do XXIV Encontro da ANPAD. 
Florianópolis: 2000.

GUARNERI, Lucimar da Silva. A Contabilidade e o Desenvolvimento Sustentável: Um Enfoque nas Informações Contábeis, Sociais e Ambientais da Indústria Siderúrgica. Rio de Janeiro: UERJ, 2001. Dissertação de Mestrado.

HABERMAS, Jurgen. Do Jornalismo Literário aos Meios de Comunicação de Massa. In: MARCONDES FILHO, Ciro (Org.). Imprensa e Capitalismo. São Paulo: Kairós, 1984.

HERMAN, Edward S.; CHOMSKY, Noam. A Manipulação do Público: Política e Poder Econômico no Uso da Mídia. São Paulo: Futura, 2003.

IOSCHPE, Evelyn Berg. O Balanço Social das Empresas. Folha de São Paulo, p. 1-3, 1 de abril de 1997. Documento obtido no site http://fws.uol.com.br/folio.pgi/fsp1997.nfo em 27 de setembro de 2005.

JAIME Jr., Pedro. Um Texto, Múltiplas Interpretações: Antropologia Hermenêutica e Cultura Organizacional. Revista de Administração de Empresas, v. 42, n. 4, p. 72-83, out.-nov.-dez. 2002.

KNIGHTS, D.; MORGAN, G. Corporate Strategy, Organizations and Subjectivity: a critique. Organization Studies, 12/2, 1991. p. 251-273.

KONDER, Leandro. Marx - Vida e Obra. São Paulo: Paz e Terra, 1999.

KONDER, Leandro. A Questão da Ideologia. São Paulo: Companhia das Letras, 2002.

MARX, Karl; ENGELS, Friedrich. A Ideologia Alemã: Feuerbach - A Contraposição Entre as Cosmovisões Materialista e Idealista. São Paulo: Martin Claret, 2005.

MIRANDA, Luiz Carlos et al. Balanço Social no Brasil: Como as Empresas Estão Divulgando sua Responsabilidade Social. Anais do $\mathbf{1 3}^{\mathbf{0}}$ Asian Pacific Conference on International Accounting Issues. Rio de Janeiro: 2001. Texto em CD-ROM.

MOTTA, F. C. P. As empresas e a transmissão da ideologia. Revista de Administração de Empresas. Rio de Janeiro: FGV. 24 (3), julho-setembro, 1984. p. 19-24.

NASSIF, Luís. O Balanço Social das Empresas. Folha de São Paulo, p. 2-3, 16 de maio de 1997. Documento obtido no site http://fws.uol.com.br/folio.pgi/fsp1997.nfo em 27 de setembro de 2005.

OLIVEIRA, José Antonio Puppim de. Um Balanço dos Balanços Sociais das 500 Maiores Empresas S.A. Não-financeiras do Brasil. Anais do $\mathbf{2 7}^{\circ}$ Enanpad. Atibaia: 2003. Texto em CD-ROM.

PINTO, Anacleto Laurino; RIBEIRO, Maísa de Souza. Balanço Social: Avaliação de Informações Fornecidas por Empresas Industriais Situadas no Estado de Santa Catarina. Revista Contabilidade \& Finanças, 15 (36): 21-34, setembro/dezembro 2004.

PINTO, Luis Fernando da Silva. Gestão-Cidadã: ações estratégicas para a participação social Siqueira, J. R. M.; Costa, A. S. M.; Sancovschi, M.; Silva, T. M. O.; Carvalho, C. D. C. 
no Brasil. 2 ed. Rio de Janeiro: Editora FGV, 2003.

PRADO, Maeli. Febraban foi Pioneira em Balanço Social. Folha de São Paulo, p. B6, 13 de julho de 2003. Documento obtido no site http://fws.uol.com.br/folio.pgi/fsp2003.nfo em 12 de agosto de 2005.

RIBEIRO, Maisa S.; LISBOA, Lázaro P. Balanço Social: Instrumento de divulgação da interação da empresa com a sociedade. Anais do XXIII ENANPAD. Foz do Iguaçu, 1999.

RIBEIRO, Silvia Basílio. Novo Executivo Deve Abraçar o Mundo. Folha de São Paulo, p. 8, 2 de novembro de 2003. Documento obtido no site http://fws.uol.com.br/folio.pgi/fsp2003.nfo em 12 de agosto de 2005.

RIOLI, Vladimir. Balanço Social. Folha de São Paulo, p. 2-2, 16 de julho de 1997. Documento obtido no site http://fws.uol.com.br/folio.pgi/fsp1997.nfo em 27 de setembro de 2005.

SCARBIERI, Astrid N. Discurso, Gênero, Ideologia e Política no Brasil. Anais do VI ALED, Santiago do Chile, 2005.

SILVA, Ana Paula Ferreira da et al. A Demonstração de Valor Adicionado como Alternativa de Medição do Desempenho Gerencial: Um Estudo Comparativo entre Demonstrações Nacionais e Internacionais. Anais do $\mathbf{1}^{\mathbf{0}}$ Seminário USP de Contabilidade. São Paulo: 2001. Texto em CD-ROM.

SILVA, César Augusto Tibúrcio; FREIRE, Fátima de Souza. Balanço Social Abrangente: Um Novo Instrumento para a Responsabilidade Social das Empresas. Anais do $25^{\circ}$ Enanpad. Campinas: 2001. Texto em CD-ROM.

SIQUEIRA, J. R. M. e VIDAL, M. C. R. Balanços Sociais Brasileiros: Uma Análise de seu Estágio Atual. Anais do $3^{\circ}$ Congresso USP de Controladoria e Contabilidade. São Paulo: 2003. Texto em CD-ROM.

SOUZA, Herbert de. Balanço Social nas Empresas Públicas. Folha de São Paulo, p. 1-3, 6 de maio de 1997. Documento obtido no site http://fws.uol.com.br/folio.pgi/fsp1997.nfo em 27 de setembro de 2005.

SOUZA, Herbert de. Balanço Social: Voluntário ou Obrigatório?. Folha de São Paulo, p. 13, 7 de abril de 1997a. Documento obtido no site http://fws.uol.com.br/folio.pgi/fsp1997.nfo em 27 de setembro de 2005.

STEINBRUCH, Benjamin. Um Bom Negócio para Todos. Folha de São Paulo, p. 2-2, 11 de agosto de 1998. Documento obtido no site http://fws.uol.com.br/folio.pgi/fsp1998.nfo em 27 de setembro de 2005.

SUPLICY, Marta. O que é Balanço Social?. Folha de São Paulo, p. 1-3, 10 de junho de 1997. Documento obtido no site http://fws.uol.com.br/folio.pgi/fsp1997.nfo em 27 de setembro de 2005. 
VENTURA, Elvira Cruvinel Ferreira. Responsabilidade Social das Empresas sob a Óptica do "Novo Espírito do Capitalismo". Anais do $27^{\circ}$ Enanpad. Atibaia: 2003. Texto em CD-ROM.

VILlELA, Milú. Respeito e Responsabilidade Social. Folha de São Paulo, p. 1-3, 26 de julho de 1999. Documento obtido no site http://fws.uol.com.br/folio.pgi/fsp1999.nfo em 12 de agosto de 2005.

YOUNG, Ricardo. Balanço Social é Responsabilidade do Governo. Folha de São Paulo, p. 2-2, 29 de março de 1997. Documento obtido no site http://fws.uol.com.br/folio.pgi/fsp1997.nfo em 27 de setembro de 2005.

ZANELLA, Fernando C.; DAVID, Afonso R. O Balanço Social como Fonte de Investigação Científica: A Relação entre Lucros e Salários. Anais do XXVI ENANPAD. Salvador, 2002. 